\title{
Consciência Crítica e Emancipação Cultural em Legados (Sul) Africanos da Comunicação para a Mudança Social
}

\section{Critical Consciousness and Cultural Emancipation in (South) African Heritages of Communication for Social Change}

\author{
C O L IN CHAS I \\ University of the Free State, Department of Communication Studies. Johannesburg - Gauteng, África do Sul \\ Y LVA RODNY-GUMEDE \\ University of Johannesburg, Department of Journalism, Film and Television. Johannesburg - Gauteng, \\ África do Sul
}

\section{RESUMO}

Neste artigo, reconhecemos o pensamento freiriano como fundamental para a articulação de um dos quatro principais fluxos de influência às abordagens sul-africanas de comunicação e mudança social. Sabelo Ndlovu-Gatsheni (2017) afirmou que os estudos universitários na África têm três influências civilizacionais: "As próprias ricas culturas/ tradições da África, as culturas/tradições islâmicas e as culturas/tradições ocidentais" (p. 54). Este relato da influência da conscientização freiriana sobre a filosofia e as práticas do movimento Consciência Negra, originário da África do Sul na década de 1960, chama a atenção para o pensamento do Consciência Negra, considerado um marco fundamental nos estudos de comunicação e mudança social.

Palavras-chave: Paulo Freire, Steve Biko, consciência crítica, Consciência Negra, África do Sul

\begin{abstract}
In this article we recognize Freirean thought as pivotal to the articulation of one of four main streams of influence on South African approaches to communication for social change. Sabelo Ndlovu-Gatsheni (2017) has contended that university scholarship in Africa has three civilizational influences: "Africa's own rich cultures/traditions, Islamic cultures/traditions, and Western cultures/traditions" (p. 54). This account of the influence of Freirean critical consciousness on the philosophy and practices of the Black Consciousness movement, which originated in South Africa in the 1960s, brings attention to Black Consciousness thought as a foundational framework for studies of communication and social change.
\end{abstract}

Keywords: Paulo Freire, Steve Biko, critical consciousness, Black Consciousness, South Africa

a Professor do Department of Communication Studies na University of the Free State. Orcid: https://orcid.org/00000002-0728-0741. E-mail: chasict@ufs.ac.za

${ }^{\mathrm{b}}$ Professora do Department of Journalism, Film and Television na University of Johannesburg. Orcid: https://orcid.org/00000002-4979-0934. E-mail: yrodny-gumede@uj.ac.za 


\section{INTRODUÇÃO}

PEDAGOGIA CRÍTICA DE Paulo Freire e a noção de conscien-
tização têm marcado fortemente o campo da comunicação para a
mudança social, mostrando que, uma vez que as pessoas podem pensar criticamente sobre sua situação específica, podem mudar suas próprias vidas e o modo como se relacionam com o mundo (Freire, 1970/2017). Em síntese, a conscientização leva à emancipação cultural.

As ideias freirianas de conscientização e emancipação cultural estão bastante impregnadas na comunicação para a mudança social, que busca usar a comunicação para promover mudanças socialmente desejáveis nas realidades vividas pelas pessoas. Suas ideias também encontram expressão nos legados africanos da comunicação para a mudança social. Recentemente, Sabelo Ndlovu-Gatsheni (2017) afirmou que os estudos universitários na África possuem três influências civilizacionais: "as próprias ricas culturas/ tradições da África, as culturas/tradições islâmicas e as culturas/tradições ocidentais" (p. 54). Essa visão dominante falha em reconhecer uma quarta tradição, que se formou na luta contra o colonialismo. Argumentaremos que essa quarta tradição é influenciada pelas ideias freirianas, ilustrando essa reflexão com aspectos da filosofia e práticas políticas do icônico líder do movimento Consciência Negra, Steve Bantu Biko. Com esse fim, notamos que Biko, sob a influência das ideias freirianas, articulou uma práxis de comunicação voltada para o aumento da consciência negra.

Vale ressaltar que, na África do Sul, Biko e Freire são figuras significativas no debate contemporâneo da descolonização. Suas ideias são fundamentais em relação ao modo como diversos intelectuais procuram imaginar o estabelecimento de uma sociedade re-humanizada na África do Sul. Dados os controversos debates em torno da comunicação para a mudança social e seu alicerce, frequentemente associado à imposição ocidental de práticas culturais, lembrar as influências freirianas sobre o movimento Consciência Negra e o alcance das reflexões que sustentam os projetos comunitários liderados por Biko, esse movimento e a quarta tradição que a Consciência Negra representa são de importância crucial para a forma como reimaginamos a comunicação para a mudança social, a partir e dentro de um contexto africano.

\section{LEGADOS AFRICANOS}

Há muitas culturas africanas. Essas culturas têm semelhanças e diferenças, e muitas vezes competem e contrastam, de modo que, quando os africanos se reúnem, frequentemente o fazem transculturalmente (Janz, 2009; Mudimbe, 
1988). No entanto, recentemente, Sabelo Ndlovu-Gatsheni (2017) ecoou, entre outros, Kwame Nkrumah (1964), ao afirmar que os estudos universitários na África possuem três influências civilizacionais: "as próprias ricas culturas/tradições da África, as culturas/tradições islâmicas e as culturas/ tradições ocidentais" (p. 54). Na verdade, Nkrumah reconheceu que a ideia de comunidades coesas na África deve muito a essas três tradições:

A sociedade africana tem um segmento que envolve nosso modo de vida tradicional; tem um segundo, decorrente da presença da tradição islâmica na África; tem um último segmento, representado pela entrada da tradição e cultura cristã da Europa Ocidental na África, usando o colonialismo e o neocolonialismo como os seus principais veículos. Esses diferentes segmentos são animados por ideologias concorrentes. Mas sociedade implica uma certa unidade dinâmica, é preciso emergir uma ideologia que, genuinamente, atendendo às necessidades de todos, tomará o lugar das ideologias concorrentes, e assim refletirá a unidade dinâmica da sociedade, e será o guia para o progresso contínuo da sociedade. (Nkrumah, 1964, p. 68)

Além do trabalho de Nkrumah (1964), que propõe que as culturas tradicionais africanas são de orientação socialista, a filosofia tradicional desenvolvida pelos africanos tem sido explorada e descrita por inúmeros intelectuais e pensadores que incluem Tempels (1959), Kaunda (1988) e Nyerere (1968), em uma história acadêmica que, desde o trabalho de Samkange e Samkange (1980), tem sido cada vez mais ensinada como evoluindo sob a noção de ubuntu (cf. Gade, 2012). Não nos propomos a rever essa tradição e a literatura sobre ela aqui. Também não propomos interrogar a história da modernidade ocidental na África - que Nkrumah classifica como a tradição do cristianismo. O que faremos é apenas observar que há uma ampla literatura que discute como a colonização ocidental da África foi, em parte, deixada a cargo de missionários que usaram proselitismo para apoiar o processo colonial (cf. Comaroff \& Comaroff, 1991). Finalmente, reconhecemos que a ideia de África é, em certos casos, produto de ligações históricas que envolvem o Islã e suas tradições (cf. Blyden, 1994; Mudimbe, 1988). Ao reconhecer que, em determinada medida, o Islã tem uma história colonial mais antiga que a do cristianismo na África, não pretendemos discutir a natureza das influências do Islã, nem avaliar os danos ou ganhos do colonialismo islâmico comparado com os do colonialismo ocidental na África. Basta dizer que, particularmente no contexto sul-africano, a herança colonial do Islã teve menos impacto, embora o Islã tenha uma base significativa neste 
país, com seus relatos convincentes da escravidão, colonialismo e apartheid mais recentes (cf. Dangor, 1997).

Nosso argumento é que a visão de que três tradições moldam a esfera intelectual africana não reconhece uma quarta tradição que informou os estudos universitários na África do Sul. Na nossa perspectiva, essa quarta tradição envolve a fusão de várias tradições que vieram antes dela no processo de trabalhar para reumanizar os oprimidos e, também, seus opressores. Falar dessa quarta tradição é, assim, atestar uma ideia racializada, que tem influências indígenas, islâmicas e ocidentais. Mas, aqui, é preciso notar rapidamente que muitas culturas africanas resolveram o problema do teor estrangeiro do Islã de maneiras complexas, e em um período muito mais longo do que foi possível com o cristianismo, cuja recente violenta emergência ainda muitas vezes se cristaliza "em torno da noção de que o encontro entre o dogma cristão e o universo local de significação foi de perda e cisão [sic] que levou ao apagamento da identidade" (Mbembe, 2017, p. 100). De fato, diante da história recente da África do Sul e de outras partes da África, é justo dizer que as identidades de muitos africanos carregam sinais da colonização ocidental (cf. Mudimbe, 1988).

Não negamos que o colonialismo ocidental destroçou todos os aparatos sociais, políticos, econômicos e psicológicos pelos quais os africanos puderam viver consigo mesmos como centros de preocupação (cf. wa Thiongo, 1993, 2009). Substituiu muitos arranjos e símbolos existentes pelos coloniais, orientados às realidades e necessidades ocidentais. Em relação à produção de conhecimento, Mbembe (2001) notou que o efeito da colonização é "que, embora agora saibamos quase tudo o que estados, sociedades e economias africanas não são, ainda não sabemos absolutamente nada sobre o que eles realmente são" (p. 9) porque lemos a partir de uma imaginação social e política que é ocidental e que transforma os africanos em outros (p. 11).

Da maneira parecida, como Fanon (1986, p. 163) afirma, é impossível compreender identidades e culturas coloniais e pós-coloniais sem pensar nas identidades e histórias racializadas, pelas quais os africanos se comparam com outros povos racializados. Isso também quer dizer que os conhecimentos africanos, mesmo os autoconhecimentos, estão fundamentalmente ligados aos vestígios coloniais. Assim, se os modos africanos contemporâneos de pertencimento surgem como problemas pós-coloniais exemplares, da mesma forma, as identidades que os africanos criaram como soluções para os problemas coloniais que enfrentam constituem novas sínteses que evidenciam a luta contra o colonialismo e o apartheid (Chipkin, 2007). Mesmo sob condições de opressão colonial, a agência dos africanos tem sido expressa em termos de como "tanto o 
Cristianismo quanto o Islã foram situados, absorvidos, transformados e reconfigurados na África" (Dubois, 2017, pp. xii-xiii).

A partir desse ponto de vista, a discussão que apresentaremos a seguir, sobre as perspectivas de Biko sobre o movimento Consciência Negra, pode ser lida como a celebração de que alguma coisa dos legados e perspectivas africanas sobreviveu. Assim, longe de entender a colônia como um estágio de destruição total das culturas, histórias e perspectivas cósmicas africanas, ela pode ser pensada como um caldeirão no qual as culturas, histórias e perspectivas cósmicas se apoiam umas às outras para dar origem a algo novo (wa Thiongo, 2012, p. 52). Ao mesmo tempo, as culturas nativas e coloniais, histórias e cosmologias permanecem reconhecíveis, de modo que se pode dizer que:

Em sua luta, o senhor imperial e o colonizado deixam marcas um no outro, mas com a diferença de que o colonizado pode se apropriar do melhor do insumo imperial e combiná-lo com o seu melhor em uma nova síntese que assume o "globo como teatro". O pós-colonial incorpora essa nova síntese. Embora tenha sua própria particularidade, como tudo que é tributário do ser humano, o pós-colonial é parte integrante da história intelectual do mundo moderno, porque sua própria colonialidade é uma história de interpenetração de diferentes povos, culturas e conhecimentos. (wa Thiongo, 2012, p. 51)

Para repetir e enfatizar o ponto central dessa perspectiva, a luta contra o colonialismo e seus legados envolve (re)clamar as subjetividades dos oprimidos para "se apropriar do melhor do insumo imperial e combiná-lo com o seu melhor em uma nova síntese" (wa Thiongo, 2012, p. 51). Steve Biko (1987) descreveu bem essa ideia quando disse:

você sabe, as culturas afetam umas às outras, como as modas, e você não consegue escapar da fricção contra a cultura de outra pessoa. Mas você deve ter o direito de rejeitar ou não qualquer coisa que lhe seja dada. No momento, existimos como um anexo da cultura branca. (p. 130)

Para entender a contribuição de Biko para o projeto decolonial, precisamos localizá-la em uma tradição mais ampla de oposição ao colonialismo. Essa ampla tradição de influências radicais do sul não é uma peça das ricas culturas/tradições africanas, culturas/tradições islâmicas e culturas/ tradições ocidentais de que Ndlovu-Gatsheni fala - é, em vez disso, uma nova síntese dessas tradições anteriores, constituída por meio do engajamento com poderosas reflexões radicais negras e do sul, como as de Fanon e de Freire. 


\section{BIKO E A CONSCIÊNCIA NEGRA}

O líder icônico do movimento Consciência Negra Steve Bantu Biko baseou-se no pensamento anticolonial de Franz Fanon e de Paulo Freire para dar uma contribuição vital para a articulação de uma quarta herança que sustenta os estudos acadêmicos na África do Sul. Mas precisamos ter cuidado para não omitir como o contexto cultural nativo de Biko influenciou seu pensamento. De fato, Manchu (2017), no segundo capítulo de Biko: A Biography, destaca fortemente esse aspecto, ao apontar como a resistência de Biko à dominação colonial é uma continuação de uma tradição de resistência que inclui personagens heroicos como Xhosa e líderes globais renomados como Martin Luther King, Mahatma Gandhi e Nelson Mandela; e pode-se argumentar que o Consciência Negra é uma extensão da Tradição Radical Negra que se manifesta em todo o mundo, na qual pessoas de ascendência africana confrontam a escravidão, o colonialismo, o apartheid e outras formas modernas de dominação ocidental (cf. Modiri, 2017; Robinson, 1983).

De fato, o movimento Consciência Negra se desenvolveu no final da década de 1960, a partir de encontros de jovens negros, ávidos leitores de textos que aguçavam seu pensamento sobre seu crescente envolvimento na política estudantil da época. Suas leituras abrangiam o trabalho de escritores como Paulo Freire, Amilcar Cabral, Frantz Fanon, Malcolm X, Martin Luther King Jr, Chinua Achebe e James Ngugi (Pityana, 2008). O Consciência Negra também se baseou nas ideias do black power e dos movimentos de direitos civis nos Estados Unidos, dos pioneiros movimentos nacionalistas africanos, da negritude de Senghor e outros, bem como em influências do movimento pan-africano, para forjar um modo de vida desafiador da dominação colonial (Pityana, 2008). Mas, na visão de Joel Modiri (2017, p. 102), que escreveu uma robusta tese de doutorado sobre o pensamento jurisprudencial de Biko, as preocupações do movimento Consciência Negra - autoconfiança, unidade e libertação foram extraídas do trabalho de Paulo Freire, em particular, da Pedagogia do Oprimido (cf. Modiri, 2017, p. 102). Pois, como Freire escreveu:

Nenhuma pedagogia que seja verdadeiramente libertadora pode permanecer distante do oprimido, tratando-os como infelizes e apresentando-os aos seus modelos de emulação entre os opressores. Os oprimidos devem ser o seu próprio exemplo na luta pela sua redenção. (Freire, 1970/2017, p. 54)

Embora seja interessante notar que o livro Pedagogia do Oprimido (1970/2017) de Freire esteja, ao menos em parte, em diálogo com Os Condenados da Terra de Fanon (1963), o importante é que Biko usou ambas as fontes para articular uma práxis voltada para a libertação (cf. Gibson, 2011, p. 8). Assim, Biko percebeu 
que, para sobreviver à opressão colonial, muitos negros recorreram a formas de consciência que buscavam tornar a vida suportável. Isso pode ser ilustrado na seguinte história narrada por ele:

para lidar com os problemas existentes, o homem negro desenvolve uma atitude de duas caras; posso citar um exemplo típico; havia um homem trabalhando em um de nossos projetos de eletricidade no Cabo Oriental, ele estava fazendo a instalação, um homem branco com um assistente negro. Ele tinha que estar em cima do telhado e o homem negro estava debaixo do teto e eles estavam trabalhando juntos, empurrando os fios e enfiando as varas em que os fios estão e assim por diante, e o tempo todo houve insulto, insulto, insulto do homem branco: empurre isso, seu tolo - esse tipo de conversa, e é claro que isso me incomodou; conheço o homem branco muito bem, ele fala muito bem comigo, então na hora do chá os convidamos; pergunto a ele: por que você fala assim com esse homem? E ele me diz na frente do outro cara: essa é a única língua que ele entende, ele é um tipo preguiçoso. E o negro sorriu. Perguntei-lhe se era verdade e ele disse: não, estou acostumado com ele. Então fiquei perturbado. Pensei por um momento que não entendia a sociedade negra. Depois de duas horas, voltei para esse cara, disse a ele: você está falando sério? $\mathrm{O}$ homem mudou, ficou muito amargo, me dizendo que queria sair a qualquer momento, mas o que ele poderia fazer? Ele não tem nenhuma habilidade, não tem nenhuma garantia de outro emprego, seu trabalho é para ele uma forma de segurança, ele não tem economias, se não trabalha hoje ele não pode viver amanhã, tem que trabalhar, tem que aguentar. E se tem que aceitar, não ousa mostrar nenhuma forma de atrevimento para seu chefe. Agora, acho que isso resume a atitude de duas caras do homem negro quanto a toda essa questão da existência nesse país. (Biko, 1987, pp. 102-103)

Os objetivos do Consciência Negra foram, portanto, voltados a que os oprimidos vivenciassem o mundo criticamente, de formas que os levariam invariavelmente a firmes mudanças que poderiam conduzir ao fim do colonialismo. Durante o caso que ficou conhecido como o julgamento SASO ou do Consciência Negra, nove jovens ativistas foram processados na África do Sul sob acusações de traição. Como testemunha, Biko aproveitou para expandir os princípios do Consciência Negra e declarou:

Basicamente, o Consciência Negra refere-se ao homem negro e à sua situação, e acredito que o homem negro está subordinado a duas forças neste país. Ele é, antes de tudo, oprimido por um mundo externo, por meio de máquinas institucionalizadas, por 
leis que o impedem de fazer certas coisas, por duras condições de trabalho, por salários muito baixos, por condições de vida muito difíceis, por educação ruim, tudo isso é externo a ele; e, em segundo lugar, e isso consideramos o mais importante, o homem negro desenvolveu em si mesmo um certo estado de alienação, ele se rejeita, precisamente porque ele atribui o significado de branco a tudo o que é bom, ou seja, ele associa o bem e o equipara ao branco. Isso advém de sua vida e de seu desenvolvimento desde a infância. (depoimento de Biko como testemunha durante o julgamento SASO, maio de 1976, citado em Arnold, 1979, p. 22)

A ética de libertação do Consciência Negra decorrente disso, portanto, priorizou: primeiramente, o surgimento de uma cultura crítica e criativa de luta que pudesse levar os oprimidos a um futuro humanizado; em segundo lugar, a libertação da religião e da teologia, para que não agissem como narcóticos, entorpecendo as habilidades das pessoas para se tornarem agentes da consciência crítica da luta contra a opressão colonial; e, terceiro, uma ética de solidariedade negra, que se manifestasse em projetos de desenvolvimento comunitário que também, por sua vez, buscassem conscientizar estudantes e professores. Esses programas "começaram com a alfabetização, utilizando o método psicossocial da pedagogia de Paulo Freire. Os alunos mais tarde organizavam clínicas e logo construíam escolas e centros comunitários" (Pityana, 2008, p. 9).

Após ser expulso do programa de treinamento de médicos negros da University of Natal, Biko trabalhou em três Projetos da Comunidade Negra, criados pelo movimento Consciência Negra: a Clínica Zanempilo, as Indústrias Domésticas de Njwasa, e o Fundo de Educação de Ginsberg, que estavam localizados em Zinyoka, uma vila rural no que hoje é a província do Cabo Oriental da África do Sul.

O esforço do movimento Consciência Negra para organizar clínicas para promover a consciência negra contrasta com a ação de Fanon que, em 1956, decidiu se demitir do Hospital Psiquiátrico de Blida Joinville, na Argélia. A razão principal de Fanon (1994) foi que "as condições objetivas sob as quais a psiquiatria é praticada na Argélia representavam um desafio ao bom senso" (p. 52), já que as condições anormais do domínio colonial tornaram anormal que alguém estivesse psicologicamente bem na Argélia da época. De fato, falando como testemunha no julgamento da Organização de Estudantes sul-africanos/Convenção do Povo Negro de 1963/64, Biko disse que os Programas da Comunidade Negra, incluindo a Clínica Zanempilo, tinham como objetivo ajudar as comunidades a superar atitudes derrotistas que as lógicas racistas do colonialismo e do apartheid inculcavam, mostrando que os negros poderiam 
fazer qualquer coisa que imaginassem - que não é verdade que tudo o que é bom vem da sociedade branca (Arnold, 1979).

Para Biko, alcançar o sucesso com a Clínica Zanempilo foi um modo de confrontar o progresso da história de como a soberania negra foi perdida em função do colonialismo e da dominação do apartheid. Nesse sentido, os negros mostrarem que podiam dominar a medicina ocidental foi um ato radical de resistência. De fato, um estudo de histórias orais coletadas, principalmente em 2008, mostra que: "os testemunhos revelam que, embora de curta duração, os ativistas do Consciência Negra conseguiram melhorar a saúde física e econômica de Zinyoka e restaurar um senso de dignidade humana em seus moradores" (Hadfield, 2010, p. 80). Isso é particularmente significativo, dado que, em contextos coloniais, os negros que praticam a medicina ocidental podem ser vistos por outros povos colonizados como símbolos de sua perda de soberania, como representantes do projeto da racionalidade ocidental (cf. Fanon, 1970, pp. 111-112) que, portanto, devem ser recebidos com um misto de orgulho e desprezo (Fanon, 1970, p. 113). Nessa perspectiva, a criação de Zanempilo diz muito sobre como Biko deve ser interpretado como uma continuação das tradições radicais negras que assumiram a tarefa de aproveitar as melhores e mais úteis inovações ocidentais e, portanto, da própria modernidade - para realizar a libertação dos negros oprimidos (cf. Masilela, 1996; Modiri, 2017).

No entanto, embora Hadfield (2010, p. 80) conclua que Zanempilo foi um sucesso, é preciso reconhecer que esse êxito tem a ressalva que o Movimento Consciência Negra buscava e aceitava o financiamento de pessoas brancas. Os fundos para a construção da clínica vieram de uma alemã que não conseguiu repatriar seus recursos, e a maior parte do financiamento operacional para gerenciar a clínica veio de benfeitores brancos, incluindo a AngloAmerican Corporation (cf. Manchu, 2017, p. 13). Além disso, as Indústrias Njwasa Home - que fabricavam artigos de couro e vestuário -, e o Fundo de Educação de Ginsberg - que oferecia bolsas, permitindo que alunos de destaque continuassem seus estudos - também dependiam fortemente de fontes brancas de financiamento (Stubbs, 2017, pp. 190-191). Isso cria a impressão de que os Programas da Comunidade Negra em que Biko estava envolvido não foram marcados pelos tipos de autoconfiança negra que o Consciência Negra defendia e que, portanto, fossem fracassos.

Contudo, é preciso também ver que Biko e o movimento Consciência Negra não estavam apenas envolvidos em compromissos programáticos que visavam eliminar a dominação colonial. Eles priorizaram restaurar a humanidade das pessoas cujas vidas tinham sido destituídas dessa característica por esses sistemas. Em outras palavras, o Consciência Negra, como Gordon (2008) e More (2008) 
observam, tem uma dimensão fundamentalmente existencial sob a qual a ressuscitação ontológica da humanidade começava com a restauração da dignidade e do valor dos negros oprimidos. Do ponto de vista positivo, o sucesso é obtido na medida em que são dados passos em direção ao que o presidente Mbeki mais tarde chamou de Renascimento Africano (cf. Reddy, 2009) e na medida em que os apelos contemporâneos para descolonizar o ensino superior na África do Sul tem Biko e o Consciência Negra como referências (cf. Khati, 2020; Sokhaba, 2020).

O Consciência Negra, portanto, emerge epistemicamente como uma série de práticas que são fundamentalmente relacionadas com a comunicação que busca mudanças sociais, permitindo que os oprimidos experimentem suas situações de maneiras que lhes permitam, a partir da consciência crítica, agir para alcançar a mudança necessária. É nesse sentido que o Consciência Negra destaca o papel da emancipação na comunicação para a mudança social.

\section{COMUNICAÇÃO PARA A MUDANÇA SOCIAL}

Chasi (2020) argumenta que a comunicação de e sobre a dor é uma preocupação subjacente da comunicação para a mudança social. Nessa perspectiva, a comunicação para a mudança social se baseia em medidas sociais para melhorar as condições de vida das pessoas - ao elevar a consciência crítica e a construção de capacidades de lidar com a dor e suas causas, de modo a permitir que as pessoas a previnam, bem como suas causas.

Biko (1987, pp. 64-65) repetidamente criticou práticas comunicativas que não apenas enfatizavam a emancipação cultural entre os negros, mas também produziam jogos de imagens e práticas de integração entre raças sul-africanas, descrevendo-as em alguns casos como soporíferas, pelo modo como embotavam as dolorosas experiências de segregação e subjugação injustas.

Algo dessa preocupação em permitir que as pessoas se relacionem com a dor de suas situações - para que possam questionar a situação e mudá-la também, é capturado nas palavras finais de Fanon (1986) em Pele Negra, Máscaras Brancas: "ó meu corpo, me faça sempre um homem que questiona" (p. 232).

O Consciência Negra está totalmente engajado com as implicações históricas da privação do legado histórico, político, social e econômico dos negros; por isso, sua episteme clama positivamente pela solidariedade negra para construir as capacidades necessárias para superar os sistemas de colonialismo e suas sujeições. De fato, por exemplo, em suas críticas aos negros que se alinharam ao sistema de autoridade do apartheid, Biko (1987) os lamenta como "falsos palanques, esses telefones mentirosos" (p. 84) - 
pois ele entendeu que o que está em jogo é a falta de comunicação da dor e do sofrimento dos oprimidos que, consequentemente, leva à incapacidade de lutar pela humanização da sociedade.

No fundo, o que é positivo sobre o Consciência Negra é que ele envolve convocar os oprimidos não para a mera "rejeição reacionária dos brancos", mas a se engajar no "jogo da política do poder", construindo fortes fundamentos institucionais a partir dos quais operar "para ascender e alcançar o eu imaginado" (Biko, 1987, p. 68). Como Ndebele (2017) diz:

"O eu imaginado" foi o conceito futurista de Biko, pelo qual ele clamava mais do que apenas pela recuperação de uma essência humana desmembrada, distorcida, desorientada, oprimida, mas também por como essa essência poderia ser recuperada e remodelada sob novas circunstâncias históricas, que abrangem mais de cento e cinquenta anos de um esforço doloroso, mas proposital, de tentar reconstitui-la em um novo ser humano. (p. x)

A busca do Consciência Negra por eliminar o colonialismo e o apartheid requer o reconhecimento de que toda atividade cultural humana envolve a sanção comunicativa de fundamentos e normas comuns, a partir das quais as pessoas constroem e praticam o bem. O Consciência Negra, portanto, se posiciona contra as narrativas e as práticas do apartheid colonial que, injustamente, levam os negros a serem diferentes e, portanto, maus, ruins, desviantes, prejudiciais ou perigosos. Sob o apartheid colonial, os negros eram marcados como grosseiramente diferentes e sua negritude era colocada em primeiro plano como um catalisador para os sentimentos entre os brancos de que eles estavam sujeitos a um swart gevaar (perigo negro). Esse tipo de demarcação de grupos externos justifica e produz o que uma teoria acomodacional da comunicação chama de divergência nas sociedades (cf. Gallois \& Callan, 1991, p. 264) e é, portanto, sustentáculo dos maniqueísmos coloniais e do apartheid - como bem narrado por Fanon (1986) em sua obra Pele Negra, Máscaras Brancas. Nas palavras do próprio Biko (1987), o Consciência Negra é:

a percepção pelos negros de que a arma mais poderosa nas mãos do opressor é a mente do oprimido. Uma vez que ele tenha sido tão efetivamente manipulado e controlado pelo opressor fazendo com que o oprimido acredite que ele está na dependência do homem branco, então não haverá nada que os oprimidos possam fazer que realmente assuste os poderosos senhores. (p. 68) 
O Consciência Negra, Biko (1987) afirma, "faz o homem negro se ver como um ser" e ele não vai mais "tolerar tentativas de ninguém para anular o significado de sua humanidade” (p. 68).

No entanto, separar as pessoas em grupos dentro e fora não é o que distingue as sociedades coloniais e de apartheid das outras. Em vez disso, o apartheid é misantrópico na forma como, paradigmaticamente, ataca o que Tomasello (2010) chamou de capacidade exclusivamente humana para o altruísmo, ou seja, a base como os seres humanos são caracteristicamente informativos, compartilhando e doando a partir de formas que tornam a comunicação e a cultura humanas únicas. Assim, ainda que pejorativamente, em situações cotidianas, perceber a concordância quanto a qualquer coisa que diminua a capacidade de uma pessoa de demonstrar altruísmo, cultura ou comunicação é um ataque à humanidade do indivíduo que sofre. Ao atacar a possibilidade da comunicação e cultura humanas, o colonialismo ataca as características fundamentais que moldam a forma e a função das sociedades humanizadas. O Consciência Negra reconheceu, portanto, que o fim do colonialismo e do apartheid é absolutamente indispensável para qualquer esforço para construir sociedades que tenham um rosto mais humano. Essas são preocupações que constituem a base para a emancipação cultural, como destacado em primeiro plano pela comunicação para a mudança social no contexto africano/sul-africano.

\section{CONSIDERAÇÕES FINAIS}

Juntamente com outros como Biko, Freire é um nome que aparece de modo proeminente nas discussões sul-africanas sobre como as realidades sociais podem ser alteradas para atingir fins mais desejáveis. De fato, o pensamento freiriano moldou e informou significativamente debates e ações sul-africanas que têm interesse em processos relacionados com a educação e a emancipação.

Assim, à luz dos debates contemporâneos da descolonização e dos apelos para descolonizar todas as esferas da sociedade, é válido evocar e compreender os pensamentos que sustentam o Consciência Negra. É importante ressaltar que o movimento marca uma maneira de pensar sobre os futuros africanos que é significativa não apenas na forma como coloca em primeiro plano a emancipação, mas também na práxis da comunicação para a mudança social. O eu imaginado que articulou é aquele que aspira humanizar o mundo. O Consciência Negra exige a transformação completa do sistema de modo que elimine a desumanização e, em consonância com o pensamento freiriano, diz que, uma vez que as pessoas são conscientizadas, elas são levadas a usar suas capacidades para tornar o mundo mais desejável e, portanto, mais humanizado, "pois não podemos estar 
conscientes de nós mesmos e ainda permanecer em cativeiro. Queremos alcançar o eu imaginado que é um eu livre" (Biko, 1987, p. 49). Fazemos bem em recordar isso nos apelos contemporâneos pela descolonização e na comunicação para a mudança social. Como tal, o Consciência Negra fundamentado - em aspectos importantes - no pensamento freiriano, bem como em outras tradições próprias da África e do Sul global, merece um sério engajamento acadêmico. Visto por essa lente, o Consciência Negra se soma tanto à teorização quanto à práxis do campo da comunicação para a mudança social.

\section{REFERÊNCIAS}

Arnold, M. W. (Ed.). (1979). The testimony of Steve Biko. M.T Smith.

Biko, S. (1987). I write what I like. Heinemann.

Blyden, E. W. (1994). Christianity, Islam and the negro race. Black Classic Press. Chasi, C. (2020). The work of pain in communication for social change. In T. Tufte \& J. Tacchi (Eds.), Communicating for change: Concepts to think with (pp. 155-165). Palgrave Macmillan.

Chipkin, I. (2007). Do South Africans exist? Nationalism, democracy and the identity of 'the people'. Wits University.

Comaroff, J., \& Comaroff J. (1991). Of revelation and revolution: Christianity, colonialism, and consciousness in South Africa (Vol. 1). University of Chicago Press.

Dangor, S. (1997). The expression of Islam in South Africa. Journal of Muslim Minority Affairs, 17(1), 141-151. https://doi.org/10.1080/13602009708716364

Dubois, L. (2017). Translator's note. In A. Mbembe, Critique of black reason (pp. ix-xv). Duke University.

Fanon, F. (1963). The wretched of the earth [Os condenados da terra] (C. Farrington, Trad.). Grove Press.

Fanon, F. (1970). A dying colonialism. Pluto Press.

Fanon, F. (1986). Black skin, white masks [Pele negra, máscaras brancas]. Pluto.

Fanon, F. (1994). Toward the African revolution: Political essays (H. Chevalier, Trad.). Grove Press.

Freire, P. (2017). Pedagogy of the oppressed [Pedagogia do oprimido]. Penguin. (Trabalho original publicado em 1970)

Gade, C. (2012). What is ubuntu? Different interpretations among South Africans of African descent. South African Journal of Philosophy, 31(3), 484-503. https://doi.org/10.1080/02580136.2012.10751789

Gallois, C., \& Callan, V. J. (1991). Interethnic accommodation: The role of norms. In H. Giles, J. Coupland, \& N. Coupland (Eds.), Studies in emotion 
and social interaction. Contexts of accommodation: Developments in applied sociolinguistics (pp. 245-269). Cambridge University Press.

Gibson, N. C. (2011). Fanonian practices in South Africa: From Steve Biko to Abahlali baseMjondolo. UKZN Press.

Gordon, L. R. (2008). A phenomenology of Biko's black consciousness. In A. Mngxitama, A. Alexander, \& N. C. Gibson (Eds.), Biko Lives!: Contesting the legacies of Steve Biko (pp. 83-94). Palgrave MacMillan.

Hadfield, L. (2010). Biko, black consciousness, and 'the system' eZinyoka: Oral history and black consciousness in practice in a rural Ciskei village, South African Historical Journal, 62(1), 78-99. https://doi.org/10.1080/02582471003778342 Janz, B. (2009). Philosophy in an African place. Lexington Books.

Kaunda, K. D. (1988). Humanism in Zambia and a guide to its implementation: Part II. Division of National Guidance.

Khati, M. (2020). Mpho Khati. In T. M. Luescher, D. Webbstock, \& N. Bhengu (Eds.), Reflections of South African student leaders 1994 to 2017 (pp. 253-276). HSRC Press.

Manchu, X. (2017). Biko: A biography. Tafelberg.

Masilela, N. (1996). The "Black Atlantic" and African Modernity in South Africa. Research in African Literatures, 27(4), 88-96.

Mbembe, A. (2001). On the postcolony. University of California.

Mbembe, A. (2017). Critique of black reason (L. Dubois, Trad.). Duke University.

Modiri, J. (2017). The jurisprudence of Steve Biko: A study in race, law and power in the "afterlife" of colonial-apartheid [Tese de doutorado, University of Pretoria]. UPSpace Institutional Repository. https://bit.ly/3kmhMhf

More, M. P. (2008). Biko: Africana existentialist philosopher. In A. Mngxitama, A. Alexander, \& N. C. Gibson (Eds.), Biko Lives!: Contesting the Legacies of Steve Biko (pp. 45-68). Palgrave MacMillan.

Mudimbe, V. Y. (1988). The invention of Africa: Gnosis, philosophy, and the order of knowledge. Indiana University.

Ndebele, N. S. (2017). Foreword: 'The Envisioned Self'. In S. Biko, I write what I like (pp. vii-xiv). Picador Africa.

Ndlovu-Gatsheni, S. J. (2017). The emergence and trajectories of struggles for an 'African university': The case of unfinished business of African epistemic decolonisation. Kronos, 43(1), 51-77. http://dx.doi. org/10.17159/2309-9585/2017/v43a4

Nkrumah, K. (1964). Consciencism: Philosophy and ideology for decolonization and development with particular reference to the African revolution. Heinemann Educational Books.

Nyerere, J. K. (1968). Ujamaa: Essays on socialism. Oxford University Press. 
Pityana, B. (2008). Reflections on 30 years since the death of Steve Biko: A legacy revisited. In C. W. Du Toit (Ed.), The legacy of Stephen Bantu Biko (pp. 1-14). University of Pretoria.

Reddy, T. (2009). Black Consciousness in contemporary South African politics. In P. Kagwanja \& K. Kondlo (Eds.), State of the Nation: South Africa 2008 (pp. 83-102). HSRC Press.

Robinson, C. J. (1983). Black Marxism: The making of the black radical tradition. The University of North Carolina Press.

Samkange, S., \& Samkange, T. M. (1980). Hunhuism or ubuntuism: A Zimbabwe indigenous political philosophy. Graham Publishing.

Sokhaba, V. C. (2020). Vuyani Ceassario Sokhaba. In T. M. Luescher, D. Webbstock, \& N. Bhengu (Eds.), Reflections of South African student leaders 1994 to 2017 (pp. 230-252). HSRC Press.

Stubbs, A. (2017). Martyr of hope: A personal memoir by Aelred Stubbs C. R. In S. Biko, I write what I like (pp. 175-244). Picador Africa.

Tempels, P. (1959). Bantu philosophy. Presence Africaine.

Tomasello, M. (2010). Origins of human communication. MIT Press.

wa Thiongo, N. (1993). Moving the centre: The struggle for cultural freedoms. James Currey.

wa Thiongo, N. (2009). Something torn and new: An African renaissance. Basic Civitas Books.

wa Thiong'o, N. (2012). Globalectics: Theory and the politics of knowing. Columbia University Press.

Artigo recebido em $1^{\circ}$ de julho e aprovado em 9 de setembro de 2021. 